\title{
FAMILIARIDADE OU \\ CONVENCIONALIDADE? \\ INVESTIGANDO FATORES \\ RELEVANTES NO \\ PROCESSAMENTO \\ DE METÁFORAS
}

\author{
Gladiston Alves da SILVA (D \\ Universidade Federal Fluminense (UFF)
}

open access

\section{EDITORES}

- Miguel Oliveira, Jr. (UFAL)

- René Almeida (UFS)

\section{AVALIADORES}

- Dalby Dienstbach (UFF)

- Mercedes Marcilese (UFJF)

DATAS

- Recebido: 06/08/2021

- Aceito: 03/09/2021

- Publicado: 11/09/2021

\section{COMO CITAR}

SILVA, Gladiston Alves (2021). Familiaridade ou convencionalidade? Investigando fatores relevantes no processamento de metáforas. Cadernos de Linguística, v. 2, n. 4, e466.
RESUMO

Metáforas são processadas pelo ouvinte mais lentamente que expressões literais? Em que medida a familiaridade do falante com as expressões metafóricas pode acelerar o processo de compreensão das mesmas? Estudos sobre o processamento da metáfora apresentam divergências quanto ao modo como essa figura de linguagem é interpretada. Alguns autores defendem que metáforas são processadas mais lentamente que expressões literais, tendo em vista a necessidade de observar os três estágios para a compreensão previstos no Modelo Pragmático Padrão (SEARLE, 1979). Evidências do processamento indireto das metáforas, compatíveis com o referido modelo, são reportadas na literatura (JANUS e BEVER, 1985). A prioridade do sentido literal sobre o metafórico tem sido, no entanto, questionado por outros estudos que defendem o processamento direto das expressões metafóricas (GLUCKSBERG, 2003; RICCI, 2016). Uma terceira onda teórica visa a conciliar as teorias, até então, conflitantes, propondo que, a depender do grau de convencionalidade do veículo metafórico, uma metáfora pode ser processada mais lentamente ou no mesmo tempo das expressões literais (BOWDLE e GENTNER, 2005). Nesse arcabouço, nosso estudo resgata a importância da familiaridade já indicada como um fator relevante em estudo experimental prévio (SILVA, 2018). Aqui, 
apresentamos novas evidências, com base em experimento psicolinguístico de leitura autocadenciada de que o controle efetivo do processamento cognitivo da metáfora recai sobre a familiaridade da expressão e não sobre a convencionalidade do veículo, como vem sendo apontado pela maioria dos teóricos.

\section{ABSTRACT}

Are metaphors processed by the listener more slowly than literal expressions? To what extent can the speaker's familiarity with metaphorical expressions accelerate the process of understanding them? Studies on metaphor processing show divergences as to how this figure of speech is interpreted. Some authors argue that metaphors are processed more slowly than literal expressions, given the need to observe the three stages for understanding provided for in the Standard Pragmatic Model (SEARLE, 1979). Evidence of the indirect processing of metaphors, compatible with the aforementioned model, is reported in the literature (JANUS and BEVER, 1985). The priority of literal over metaphorical meaning has, however, been questioned by other studies that defend the direct processing of metaphorical expressions (GLUCKSBERG, 2003; RICCI, 2016). A third theoretical wave aims to reconcile the hitherto conflicting theories, proposing that, depending on the degree of conventionality of the metaphorical vehicle, a metaphor can be processed more slowly or at the same time as literal expressions (BOWDLE and GENTNER, 2005). In this framework, our study rescues the importance of familiarity already indicated as a relevant factor in a previous experimental study (SILVA, 2018). Here, we present new evidence, based on a psycholinguistic self-paced reading experiment, that the effective control of the metaphor's cognitive processing rests on the familiarity of the expression and not on the conventionality of the vehicle, as has been pointed out by most theorists.

\section{PALAVRAS-CHAVE}

Psicolinguística; Processamento; Metáfora; Familiaridade;

Convencionalidade.

\section{KEYWORDS}

Metaphors; Psycholinguistic; Processing; Familiarity; Conventionality. 


\title{
INTRODUÇÃO
}

Quando se fala em metáfora, logo se imagina uma figura de linguagem diretamente ligada às obras literárias. Esse imaginário vem sendo mudado, uma vez que há o reconhecimento do uso diário da metáfora na interação social. Nesse sentido, é importante destacar o trabalho pioneiro de Lakoff \& Johnson (2002 [1980], que apontam para o fato de que o indivíduo enxerga o mundo através de suas próprias experiências, o que gera um modo especial de se expressar com base num sistema conceptual organizado de forma metafórica. Afirmam os autores:

\begin{abstract}
Os conceitos que governam nosso pensamento não são meras questões do intelecto. Eles governam também a nossa atividade cotidiana até nos detalhes mais triviais. Eles estruturam o que percebemos, a maneira como nos comportamos no mundo e o modo como nos relacionamos com pessoas (LAKOFF \& JOHNSON, p.45-46, 2002 [1980])
\end{abstract}

Assim, o homem se comunica usando metáforas naturalmente, muito embora, paradoxalmente, elas violem as máximas da interação postuladas por Grice (1975), tendo em vista que, da perspectiva da literalidade, estamos diante de falsas declarações. Em outras palavras, diante de uma expressão como 'Alguns carros são abacaxis', ao quebrarse à lógica literal da frase, viola-se a máxima da qualidade formulada por Grice, pois se afirma algo notoriamente não verdadeiro. Nesse sentido, para corrigir a pseudoimperfeição do exemplo citado, seria necessário algum tipo de "correção" por parte do ouvinte/falante durante o processamento da frase. Para alguns pesquisadores, a necessidade de ocorrer tal "ajuste" para alcançar a compreensão, envolveria, primeiramente, a interpretação literal da frase pelo ouvinte/leitor, para só posteriormente buscar uma interpretação não literal adequada à construção proposta pelo falante. Tal procedimento, teorizado ainda na época de Aristóteles, foi desenhado modernamente por Searle (1979) e denominado de Standard Pragmatic Model (SPM), ou seja, Modelo Pragmático Padrão. Tal modelo recebeu algumas críticas de outros estudiosos da área, como Glucksberg (2003), que contesta essa prioridade do literal para a compreensão de frases metafóricas socialmente convencionalizadas.

É importante esclarecer neste momento, ainda que de forma preliminar, que as expressões metafóricas estudadas na pesquisa aqui reportada são frases nominais, representadas pela fórmula 'X é um Y', adaptada para o Português Brasileiro (PB) por Ricci (2016) para a fórmula 'Alguns $X$ são $Y$ '. Aqui também vale esclarecer que o argumento ' $X$ ', necessariamente, é o tópico da expressão e é o seu sentido que deve ser alterado ou transportado para esfera de domínio de outra palavra, enquanto que o argumento ' $Y$ ' é o veículo metafórico, ou seja, a palavra que cuidará do transporte do sentido do tópico para esfera de seu domínio. Por exemplo, na expressão 'Alguns carros são abacaxis', a palavra 'carro' se refere ao tópico ' $X$ ' e a palavra 'abacaxi' se refere ao veículo ' $Y$ ', sendo que, nesse 
caso, é 'carro' que precisa ter seu sentido transportado para esfera de domínio da palavra 'abacaxi', para então ser interpretada no sentido de que alguns carros são problemáticos e apresentam defeitos constantemente.

Dessa forma, de acordo com a proposta do SPM a frase 'Alguns carros são abacaxis' deveria ser interpretada primeiramente no seu sentido literal, podendo assim ser parafraseada como: 'Alguns carros são plantas terrestres'. Desse modo, não havendo coerência nessa propositura, se passaria a um segundo estágio de análise das características entre tópico e veículo para, assim, num terceiro momento, retirar uma interpretação não-literal adequada: 'Alguns carros são problemáticos'. Entretanto, resta claro que a interpretação dentro desse modelo é bem mais trabalhosa, demandando um tempo maior para o falante/leitor chegar ao sentido pretendido da frase ouvida/lida, uma vez que o processo de comparação de características entre duas palavras de domínios diferentes e sua posterior adequação ao processo interativo demandaria um esforço cognitivo muito maior.

Por outro lado, outros pesquisadores, como é caso daqueles que se dedicam aos estudos da metáfora como inclusão de categoria, como, por exemplo, Glucksberg (2003) e Ricci (2016), contestam as assunções do SPM, pois, para eles, frases metafóricas socialmente convencionalizadas não envolveriam custos adicionais de processamento, uma vez que o ouvinte/leitor teria o domínio das categorias propostas pelos veículos metafóricos e, assim, ao se deparar com uma expressão desse tipo, faria a ligação direta entre o veículo metafórico e a respectiva categoria a que ele pertence, isso sem demandar qualquer esforço ou tempo extra. No exemplo apresentado, o termo 'abacaxi' está convencionalizado no PB como sendo um veículo metafórico que se refere a uma categoria de coisas problemáticas, então para o ouvinte/leitor basta enquadrar o sentido do tópico, seja ele qual for, nessa esfera de domínio, ou seja, 'Alguns ônibus são abacaxis', 'Algumas pontes são abacaxis' e 'Algumas barcas são abacaxis', por exemplo. Dessa forma, todos esses tópicos podem ser entendidos pelos falantes diretamente como algo que apresenta dificuldade em seu uso em face de apresentar problemas insuperáveis, pois estão na esfera do sentido metafórico do veículo 'abacaxi', que produz a categoria de coisas problemáticas e que já é do conhecimento do falante da língua.

Outra questão importante diz respeito à base de sustentação da metáfora, pois é inimaginável que qualquer palavra aleatória possa ser utilizada arbitrariamente como veículo metafórico e, ao mesmo tempo, ser compreendida por todos os falantes de uma língua. Para que uma metáfora seja estabelecida, cristalizada ou se torne permanente na língua, é preciso que ela seja sustentada por uma base fixa que, nesse caso, é formada pelo tripé: 'convencionalidade', 'familiaridade' e 'aptness' (ou “adequação”, em tradução livre). Esse tripé pode ser representado pela figura 1 abaixo. 


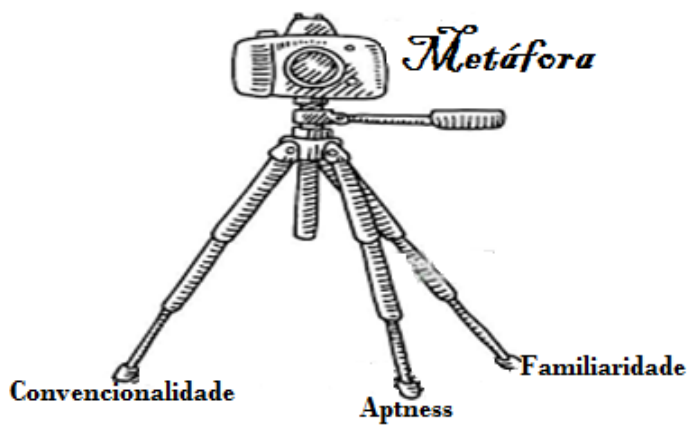

Figura 1. Representação do tripé metafórico.

As frases metafóricas, objeto deste estudo, como dito anteriormente, são do tipo nominal e representadas pela fórmula 'Alguns $X$ são $Y$ '. Partindo do pressuposto de que essas frases metafóricas possuem sua sustentação no equilíbrio do tripé antes mencionado, a pesquisa aqui reportada buscará avaliar a relevância efetiva de cada um desses três eixos no processamento linguístico.

A 'convencionalidade' diz respeito especificamente ao veículo metafórico, ou seja, o ' $Y$ ' da nossa fórmula. É essa palavra, representada pelo ' $Y$ ', que está inserida no dicionário mental não só com seu sentido literal, mas também com seu sentido figurado. A palavra ganhou polissemia justamente por ser usada metaforicamente para significar algo diferente daquilo que literalmente significa. A 'familiaridade', por sua vez, se refere à própria frase metafórica construída, isto é, a familiaridade não se limita apenas ao veículo metafórico, pelo contrário, além de englobar o veículo $(Y)$, inclui também o tópico $(X)$, além de todas as palavras presentes na expressão, portanto, qualquer mudança na estrutura da frase pode alterar o grau de familiaridade de uma expressão, pois este aspecto do tripé é extremamente sensível às mudanças de determinantes em frases nominais (ex. a introdução de um adjetivo na expressão "X é um abacaxi" potencialmente pode provocar o não reconhecimento da mesma como uma metáfora - cf. "X é um abacaxi maduro"). $O$ 'aptness, por fim, está relacionado diretamente ao equilíbrio entre tópico $(X)$ e veículo $(Y)$, isso quer dizer que é necessário verificar o quanto é adequado o uso de um dado tópico em relação a um dado veículo metafórico. Frases metafóricas do tipo nominal que apresentam adequação elevada entre tópico e veículo, em tese, poderiam ser processadas mais facilmente pelo ouvinte/leitor independentemente de serem elas novas ou convencionalizadas. Os três fatores serão retomados em tópico específico nas próximas seções do artigo.

Feitas essas considerações preliminares, é possível constatar que a 'convencionalidade', dentro do tripé, é a que possui critérios mais objetivos para sua caracterização. Isso ocorre porque ela é facilmente verificável a partir de uma rápida 
pesquisa em um dicionário da língua estudada. Tal assertiva não vale nem para 'familiaridade' nem para 'aptness', cuja avaliação não pode ser feita de forma direta, mas requer a coleta e análise de dados para sua efetiva verificação. Desta feita, justamente em face dessa maior facilidade em identificar um veículo metafórico pela sua convencionalidade é que a maioria das pesquisas na área de processamento psicolinguístico de metáforas tem usado esse fator como ponto de partida. Nessa linha de estudo, se enquadram os trabalhos de Glucksberg e Keysar (1990), Glucksberg (1998), Glucksberg (2003), Ricci (2016) e Bowdle e Gentner (2005), entre outros.

Diante deste cenário, a presente pesquisa tem o foco voltado para a 'familiaridade' do 'tripé metafórico' e, mais precisamente, para o desnivelamento desse apoio em relação à 'convencionalidade'. Note-se que, na representação da figura 1, a metáfora equivale à máquina fotográfica, enquanto cada pé do equipamento representa ou a convencionalidade, ou a familiaridade ou a aptness. Levando em consideração os ensinamentos de Lakoff \& Johnson, para cima estaria a positividade, enquanto que para baixo a negatividade. Sendo assim, quanto mais alto os eixos do tripé, melhor a compreensão da metáfora (portanto, processamento direto pela rapidez da interpretação). Por outro lado, quanto mais baixo esses eixos, maior dificuldade na compreensão da metáfora (portanto, processamento indireto pela lentidão da interpretação). Desnivelar o tripé metafórico, nesse caso, significa diminuir o eixo da convencionalidade e, ao mesmo tempo, deixar o eixo da familiaridade em posição alta, para então verificar se o tempo de compreensão da expressão metafórica se dá por cima ou por baixo, ou seja, se acompanha o movimento para baixo da convencionalidade ou se mantém em alta junto com a familiaridade. Do mesmo modo, pretende-se desnivelar o eixo diminuindo a familiaridade e deixando a convencionalidade em posição alta.

Alguns dos estudos indicados aqui sugerem que a convencionalidade tem papel fundamental no processamento da metáfora e, sendo ela alta, o processamento se dá de forma rápida, ao passo que sendo ela baixa o processamento se dá mais lentamente. Desse modo, buscaram-se no ranqueamento produzido por Ricci (2016) expressões metafóricas que possuíssem alta familiaridade e, ao mesmo tempo, baixa convencionalidade, bem como expressões com baixa familiaridade e alta convencionalidade. Esse quadro é necessário para aferir se a 'familiaridade', por si só, interfere ou não no tempo de processamento de metáforas, uma vez que o trabalho de Glucksberg (2003) não levou em consideração o grau de familiaridade das expressões para construir seu estudo experimental, cujos resultados sustentam a hipótese da teoria da inclusão de classe (class-inclusion). O estudo de Ricci (2016), desenvolvido especificamente para o PB, também assume a teoria de inclusão de classe, porém, diferentemente de Glucksberg (2003), Ricci levou em consideração tanto a convencionalidade, quanto a familiaridade e o aptness das expressões. No entanto, para não fugir de seu objetivo principal, Ricci (2016) se utilizou apenas de expressões com alta 
convencionalidade, alta familiaridade e alto grau de aptness para avaliar o processamento direto dessas expressões no PB.

Nossa pesquisa visa a preencher essa lacuna quanto a investigação mais detalhada do papel da familiaridade no processamento das metáforas nominais, pois poucos são os estudos que levaram em consideração tal fator. Blasko e Connine (1993), por exemplo, consideraram a familiaridade e a aptness na construção de seus experimentos, mas ali não havia o desnivelamento do eixo em relação à convencionalidade. Silva (2018), por sua vez, tendo como base o mesmo desnivelamento proposto aqui, num estudo experimental formado por tarefas off-line, reporta dados que sugerem uma mudança de preferência pela forma gramatical (gramatical form preference task) de expressões metafóricas, ou seja, se para Bowdle e Gentner (2005), ao traçarem a carreira da metáfora, a preferência da expressão metafórica no modelo gramatical de comparação se dava com expressões metafóricas novas (ou de baixa convencionalidade), para Silva (2018) essa mesma preferência, conforme apontamento das evidências, se dava com expressões metafóricas de alta convencionalidade e baixa familiaridade. Por exemplo, a expressão 'Alguns carros são abacaxis', segundo ranqueamento de Ricci (2016), como se verá adiante, possui 98,75\% de convencionalidade e 40,74\% de familiaridade. Essa expressão foi preferida no modelo de comparação ('Alguns carros são como abacaxis'). As frases nessas condições receberam, numa escala de 0 a 5, a nota média de 3,413 pontos no modelo de comparação, enquanto no modelo de declaração a nota média ficou em 1,313 pontos. Nesse sentido, é importante deixar consignado que o presente estudo contesta pesquisas que desconsideraram ou minimizaram a importância da familiaridade no processamento da metáfora.

\section{ASPECTOS TEÓRICOS}

Os estudos sobre o processamento de metáforas têm se debruçado sobre dois aspectos principais que norteiam a direção das pesquisas. O primeiro se refere ao modelo gramatical adotado para caracterizar a compreensão de expressões metafóricas, ou seja: metáforas são mais bem compreendidas como uma declaração ou a partir de uma comparação? Em outras palavras, a interpretação seria feita a partir de uma estrutura do tipo 'Alguns carros são abacaxis' ou do tipo 'Alguns carros são como abacaxis'? O que parece mais natural para o falante, no caso, do PB? O segundo aspecto é se metáforas demandam maior tempo para serem processadas em relação às expressões literais envolvendo, portanto, processamento indireto, ou se as metáforas são processadas em latências equivalentes ao tempo de processamento das expressões literais e, nesse caso, envolveriam um processamento direto. 
Sobre o primeiro aspecto, pode-se destacar o trabalho de Bowdle e Gentner (2005), que desenvolveram a teoria da "carreira da metáfora" em que apresentam evidências de que as metáforas com alta convencionalidade são processadas por ambos os modelos gramaticais de declaração e comparação, enquanto que metáforas novas (ou de baixa convencionalidade) são processadas exclusivamente pelo modelo gramatical de comparação. Tais evidências foram obtidas por meio de experimentos off-line.

Ainda sobre esse primeiro aspecto, Silva (2018), seguindo essa mesma linha de discussão, buscou aferir a interferência da familiaridade no processamento de metáforas, replicando no PB, com as devidas adaptações, o estudo de Bowdle e Gentner (2005) na carreira da metáfora. Silva (2018), levantava a hipótese de que, por interferência da familiaridade, metáforas altamente convencionalizadas e com baixo de grau de familiaridade seriam processadas exclusivamente pelo modelo de comparação, enquanto que metáforas com baixa convencionalidade e altamente familiares seriam processadas opcionalmente pelos modelos de comparação ou declaração. As evidências encontradas após a realização de quatro experimentos off-line sugerem que, de fato, a familiaridade interfere no processamento de metáforas e muda a preferência pela aceitação de um ou outro modelo gramatical. O estudo de Silva (2018) que será ampliado e aprofundado no presente artigo.

Sobre o segundo aspecto da discussão, é importante salientar que inúmeros pesquisadores divergem quanto ao modo de processamento das metáforas. Na linha que defende o processamento indireto, destaca-se o trabalho de Searle (1979), que propõe um modelo em três estágios discretos, de acordo com o qual, no primeiro momento em que o ouvinte/leitor se depara com uma expressão metafórica, de imediato, ele constrói uma representação mental do sentido literal. Num segundo momento, essa interpretação é confrontada com o contexto para determinar sua plausibilidade e adequação. Não sendo coerente com o contexto, a interpretação inicial é rejeitada e se passa ao terceiro momento, qual seja: uma nova interpretação derivada do significado literal e do significado não literal adequada ao contexto. Tal modelo de processamento é aquele denominado de Standard Pragmatic Model (SPM, na sigla em inglês).

Nessa mesma linha de raciocínio se enquadram os estudos produzidos por Janus e Bever (1985), que reportam tempo de leitura para metáforas maiores quando comparado com a leitura das expressões literais. Outros estudos também apresentam resultados compatíveis com a ideia de que metáforas são processadas mais lentamente do que expressões literais, dentre eles, destacam-se Clark e Lucy (1975) e Gibbs (1981). As evidências apontadas por estes estudos dão o suporte ao modelo discreto de três estágios, previsto no SPM, que sugere haver o disparo de um processo em série quando um indivíduo se depara com uma expressão metafórica, sendo este mais lento do que o literal em razão 
de que o mecanismo que envolve essa interpretação metafórica se diferencia do mecanismo que envolve a interpretação literal.

Por outro lado, estudos que contestam o SPM afirmam que a interpretação de uma expressão metafórica não demanda maior tempo do que a interpretação de uma expressão literal correlata, pois, uma vez convencionalizada na língua, uma metáfora é processada como qualquer outra palavra, levando o ouvinte/leitor a processá-la automaticamente da mesma forma que o literal. Pensando justamente na via de processamento direto, Glucksberg (2003) desenvolveu estudos em que defende que o literal não possui prioridade incondicional sobre o metafórico, isto é, não necessariamente o ouvinte/leitor se direciona para o literal ao se deparar com uma expressão metafórica, uma vez que os falantes não podem ignorar as metáforas, mesmo que significados literais possam fazer sentido dentro do contexto discursivo. Com base nessa hipótese, Glucksberg (2003) desenvolveu um estudo experimental cujos resultados são compatíveis com a ideia de que as metáforas criam uma categoria específica e, partir do momento que o falante da língua tem o domínio dessa categoria, ele apenas insere os tópicos $(X)$ das expressões dentro das categorias vinculadas ao veículo (Y). Por exemplo, na expressão 'Alguns advogados são tubarões', o termo 'tubarão' pode ser usado no sentido metafórico para qualquer ser vicioso e predatório e, assim, cria-se a categoria de seres viciosos e predatórios, representado pelo veículo (Y) 'tubarão' e, havendo uma categoria assim, é possível inserir nessa categoria qualquer tópico $(X)$, como por exemplo, 'Alguns empresários são tubarões', 'Alguns banqueiros são tubarões' etc.

Glucksberg (2003) fornece evidências de que metáforas convencionalizadas na língua demandam tempo semelhante de processamento quando comparadas a expressões literais correlatas, sugerindo, com isso, que os falantes armazenam na mente uma categoria vinculada aos veículos metafóricos e, quando eles surgem na linguagem, ao indivíduo cabe apenas vincular o tópico à categoria representada pelo veículo, sem demandar qualquer esforço extra para isso. Os resultados reportados contrariam o SPM, pelo menos em relação às expressões metafóricas cujos veículos possuem maior convencionalidade na língua. $O$ estudo de Glucksberg (2003) não entrou na seara dos veículos metafóricos novos (ou de baixa convencionalidade), abrindo, assim, espaços para novas pesquisas.

Outro pesquisador que trilhou o caminho da teoria da inclusão de categoria aberto por Glucksberg (2003) foi Ricci (2016), que testou no PB essa teoria de processamento direto. Após realizar um ranqueamento de metáforas nominais para o PB, Ricci (2016) selecionou expressões metafóricas que aglutinavam em si as características de alta convencionalidade, alta familiaridade e alto aptness e realizou um experimento on-line, em que também encontrou evidências de que metáforas com essas características não demandam tempos significativamente maiores para serem processadas do que expressões literais correlatas e, desta feita, também contestou as assunções do SPM para as metáforas convencionalizadas. 


\section{TESTANDO O TEMPO DE PROCESSAMENTO DE METÁFORAS NO PB}

Na pesquisa reportada no presente artigo, para compreender o que acontece no momento em que o leitor/ouvinte se depara com uma expressão metafórica, foi realizado um experimento on-line de leitura segmentada autocadenciada. Esse experimento foi motivado pelo interesse de averiguar a interferência da familiaridade no processamento de metáforas por meio de medida on-line, uma vez que os dados de um estudo prévio (Silva, 2018) se assentam numa metodologia experimental off-line e, por esse motivo, não davam conta de responder sobre o processamento efetivamente, mas antes pela opção consciente do falante sobre uma ou outra forma gramatical da expressão metafórica (i.e. declaração ou comparação). No estudo off-line prévio, detectou-se que os falantes preferiam, de forma significativa, o modelo gramatical de comparação no caso de expressões metafóricas de baixa familiaridade e alta convencionalidade, enquanto que para expressões metafóricas de alta familiaridade e baixa convencionalidade, os falantes, opcionalmente, aceitavam tanto a forma de comparação gramatical quanto a forma de declaração gramatical. Esta evidência, a princípio, aponta para uma possível mudança no comando do processamento cognitivo da metáfora, uma vez que se atribuía à convencionalidade esse papel de acessar rapidamente ou não as estruturas que possibilitam as resoluções de metáforas. Por exemplo, 'lesma', segundo ranqueamento de Ricci (2016), na frase 'Alguns motoristas são lesmas' possui 98,73\% de convencionalidade e $100 \%$ de familiaridade para designar uma lentidão no trânsito, ao passo que 'Alguns bebês são lesmas' perde muito em familiaridade para designar a lentidão de um bebê para se amamentar. No caso dessas expressões, quem comanda o processamento é a familiaridade e, por isso, no primeiro caso ela é processada mais rapidamente e no segundo caso mais lentamente, apesar de ambas possuírem o mesmo veículo metafórico 'lesma' com alto grau de convencionalidade. O estudo experimental reportado a seguir visa ampliar e aprofundar os resultados inicialmente obtidos a partir de medidas off-line.

\subsection{LEITURA AUTOMONITORADA DE METÁFORAS}

Um experimento on-line de leitura segmentada autocadenciada foi idealizado com o objetivo de investigar o tempo de leitura de expressões metafóricas. Para tal, foram contrastadas:(1) metáforas de alta convencionalidade e baixa familiaridade; (2) metáforas de baixa convencionalidade e alta familiaridade; e (3) expressões literais correspondentes. O material experimental foi composto por frases divididas em três segmentos, sendo que o primeiro segmento se constituía do tópico da expressão, enquanto que o segundo segmento foi constituído por um verbo e um 'veículo' e, finalmente, o terceiro segmento, 
constituído por um advérbio ou equivalente, conforme detalhado mais adiante. O segmento crítico de leitura recaiu no segundo segmento, no qual os traços de convencionalidade e familiaridade foram controlados. O desenho experimental - inspirado a partir dos resultados reportados por Silva (2018) - foi concebido no intuito de se avaliar a possível interferência da familiaridade no processamento de metáforas.

\subsection{HIPÓTESES E PREVISÕES}

Com base no observado em estudo prévio em função de medidas off-line (Silva, 2018), foi aventada a hipótese de que o grau de familiaridade do falante com a expressão seria um fator mais relevante do que a convencionalidade do veículo no processamento da metáfora. Ou seja, quando a familiaridade é baixa, haveria uma tendência de as metáforas serem processadas de forma indireta (processadas mais lentamente que o seu sentido literal, portanto), enquanto que, quando a familiaridade é alta, a tendência seria que essas metáforas fossem processadas de forma direta (em tempos equivalentes ao literal). De acordo com essa hipótese, as seguintes previsões experimentais são levantadas:

(i) Espera-se que metáforas de baixa convencionalidade e alta familiaridade [-C+F] sejam processadas mais rapidamente do que metáforas de alta convencionalidade e baixa familiaridade $[+\mathrm{C}-\mathrm{F}]$;

(ii) Da mesma forma, espera-se que metáforas [+C-F] sejam processadas mais lentamente do que expressões literais respectivas;

(iii) Espera-se ainda que metáforas $[-\mathrm{C}+\mathrm{F}]$ apresentem tempos de processamento equivalentes às expressões literais.

\subsection{VARIÁVEIS E CONDIÇÕES}

Foram delimitadas duas variáveis independentes, a saber: (1) o traço familiaridade associado à expressão metafórica e (2) o traço de convencionalidade. Cada uma dessas variáveis apresenta dois níveis, um polo positivo e outro negativo. Sendo assim, a variável (1) se realiza nos níveis mais familiar (+F) e menos familiar (-F). Também a variável (2) possui dois níveis: mais convencional $(+C)$ e menos convencional $(-C)$.

Do cruzamento dos níveis de cada uma de ambas as variáveis independentes descritas acima, deveriam resultar quatro condições experimentais. No entanto, é importante destacar que esse experimento possui um desenho $2 \times 2$ apenas incompleto. Isso ocorre porque não utilizamos estímulos que possuíssem ambos os níveis de cada variável em seus polos coincidentemente positivos e negativos, ou seja, não foram projetadas frases 
metafóricas $(+\mathrm{C}+\mathrm{F})$ ou $(-\mathrm{C}-\mathrm{F})$, em razão de que nos estudos realizados por outros pesquisadores e relatados previamente aqui os polos do tripé da metáfora sempre foram calibrados com todos os seus traços em positivo. O objetivo da presente pesquisa é justamente "desequilibrar" os polos de convencionalidade e familiaridade para observar um possível efeito específico de cada um desses dois fatores. Vale destacar também que a aptness não foi investigada nesse experimento, não por ter sido controlada, mas sim por não ter sido observado esse fator na composição do experimento. .

Para além das expressões metafóricas $(+\mathrm{C}-\mathrm{F})$ e $(-\mathrm{C}+\mathrm{F})$, o experimento também contou com expressões literais respectivas às duas condições em teste. Essas expressões literais correspondem, portanto, a um controle experimental e contavam com traços $\mathrm{C}$ e $\mathrm{F}$ idênticos aos de suas versões metafóricas correspondentes.

Como variável dependente foi considerado o tempo de reação no segmento delimitado como crítico.

\subsection{PARTICIPANTES}

Participaram do experimento cem (100) estudantes universitários, divididos em dois grupos de cinquenta cada. Os grupos foram formados por 27 pessoas do sexo masculino e 23 do sexo feminino com idade média próxima de 26 anos.

\subsection{MATERIAIS}

Para a construção desse experimento, utilizou-se o programa PsyScope X B57 que permite apresentar os estímulos experimentais e gravar o tempo de reação dos participantes.

Partindo dos estudos iniciais sobre a interferência da familiaridade no processamento de metáforas, recuperaram-se aquelas mesmas expressões previamente investigadas por Ricci (2016, Apêndices A e B - Tabela B), conforme excerto abaixo.

\begin{tabular}{|l|l|l|l|l|}
\hline Posição & Expressões & Convencionalidade & Familiaridade & DIFERENÇA \\
\hline 1 & Alguns carros são abacaxis. & $98,75 \%$ & $40,74 \%$ & 58,01 \\
\hline 2 & Alguns vizinhos são sapos. & $90,51 \%$ & $41,98 \%$ & 48,53 \\
\hline 3 & Alguns jóqueis são palitos. & $96,20 \%$ & $53,09 \%$ & 43,11 \\
\hline & Algumas estradas são serpentes. & $92,41 \%$ & $58,02 \%$ & 34,39 \\
\hline 2 & & & & \\
\hline 3 & Algumas frases são pérolas. & $46,84 \%$ & $96,30 \%$ & 49,46 \\
\hline 4 & Alguns cérebros são computadores. & $48,73 \%$ & $96,30 \%$ & 47,57 \\
\hline
\end{tabular}

Tabela 1. Ranqueamento das expressões. Fonte: RICCI (2016, Apêndice A e B).

Note-se que das expressões elecandas na tabela 1, duas delas, "Algumas despesas são facadas' e 'Algumas notícias são bombas', apresentam uma certa proximidade entre convencionalidade e familiaridade. Isso ocorre em razão de que das 84 frases ranqueadas 
por Ricci (2016), apenas 6 delas se alinhavam com o objeto da presente pesquisa. Sendo assim, optou-se por incluir essas duas últimas frases para equilibrar o quadro experimental, levando-se em consideração que essas frases apresentam um distanciamento entre convencionalidade e familiaridade acima de $30 \%$ de diferença. Insta esclarecer que os resultados, mesmo levando em consideração a separação dessas duas frases, continuam consistente com a proposta da pesquisa.

A partir das expressões da tabela 1, fez-se uma divisão de segmentos com a finalidade de cronometrar o tempo de reação do participante ao se deparar com os veículos metafóricos. Ocorre que os veículos metafóricos em todas as frases surgem como última palavra e, por serem eles (os veículos) justamente os alvos do interesse da pesquisa, houve a necessidade de criarmos mais um segmento final de modo a não ocorrer nenhuma interferência (o denominado efeito de 'empacotamento' - wrapup em inglês) no tempo de processamento desse segmento específico. Por exemplo, na expressão 'Alguns carros são abacaxis', acrescentou-se um outro segmento final, ficando assim a expressão definitiva a ser avaliada: 'Alguns carros são abacaxis mesmo'. Definido esse procedimento, criaram-se os três segmentos dessa expressão, sendo eles: Primeiro segmento - Alguns carros -; Segundo segmento - são abacaxis -; Terceiro segmento - mesmo. Note-se que no primeiro segmento da expressão está disposto o tópico, enquanto que no segundo aparece o veículo metafórico e, por último, no terceiro surge um advérbio, finalizando a frase. Com essa manipulação na estrutura, espera-se que não ocorra influência do efeito empacotamento na leitura do tempo de reação do segundo segmento.

Foi utilizada ainda uma pergunta de compreensão do tipo 'sim/não'com a finalidade de reduzir as possibilidades de o participante identificar o objetivo real da pesquisa que estava sendo conduzida, uma vez que as perguntas apresentadas se referiam a conteúdos alheios ao da interpretação da metáfora. Por exemplo, após a leitura segmentada de 'Alguns carros são abacaxis mesmo', surgia a pergunta: 'A indústria automobilística brasileira é moderna?'. Além disso, foram criadas frases distratora para a composição final do desenho.

Insta ressaltar que além do grupo de condições experimentais, foi incluído um grupo de expressão de controle literal que se referia a cada uma das expressões metafóricas. Por exemplo, para a expressão 'Alguns carros são abacaxis mesmo', foi criada a expressão 'Alguns carros são valiosos mesmo.' Note-se que 'valiosos' equivale foneticamente à 'abacaxis', uma vez que possui o mesmo número de letras e o mesmo número de sílabas. Este mesmo padrão foi adotado para as demais expressões, havendo um controle bastante equilibrado nesse sentido.

O desenho do experimento, portanto, apresentava um modelo designado pela literatura de $2 \times 2$ incompleto, tendo em vista haver 2 variáveis e 2 condições, como descrito mais acima. Desta feita, representa-se na tabela 2 abaixo o formato do design. 


\begin{tabular}{|l|l|l|}
\hline & CONDIÇÕES & CONDIÇÕES \\
\hline Metáfora & $+\mathrm{C}-\mathrm{F}$ & $-\mathrm{C}+\mathrm{F}$ \\
\hline Controle & Literal+C-F & Literal-C+F \\
\hline
\end{tabular}

Tabela 2. Variáveis e condições do Experimento.

Algumas poucas diferenças ocorreram na construção das frases dos estímulos, como por exemplo, número de letras e número de sílabas. Mesmo assim, essas diferenças foram controladas, ou seja, na expressão metafórica 'Algumas estradas são serpentes de fato', criou-se a expressão literal 'Algumas estradas são perigosas de fato'. Observe-se que, nesse caso, apesar de não haver a mesma quantidade de sílabas em 'serpentes' e 'perigosas', pois na primeira há três sílabas enquanto na segunda há quatro sílabas, porém a quantidade de letras em ambas as palavras é a mesma, ou seja, nove. Frise-se também que em razão do experimento se pautar em grupos de frases, possíveis diferenças na construção foram consideradas e diluídas entre os estímulos. É importante destacar, também, que além dessas expressões foram acrescidas outras expressões distratoras que tinham como interesse desviar a atenção dos participantes das frases objeto do experimento, como por exemplo, 'A justiça mandou soltar o criminoso'

O desenho final do experimento ficou assim construído: 8 expressões metafóricas (sendo quatro do tipo+C-F e quatro do tipo $-\mathrm{C}+\mathrm{F}$ ); 8 expressões literais correlatas das expressões metafóricas (controle); 32 expressões distratoras, totalizando 48 estímulos. Tendo em vista a quantidade de expressões a serem analisadas por cada um dos participantes, decidiu-se adotar a distribuição dos estímulos intra-participantes, ou seja, todos os participantes foram expostos a ambas as condições do experimento e ao estímulo controle, razão pela qual foi necessário distribuir todos os estímulos num quadrado latino para que um participante não tivesse acesso às mesmas condições das expressões metafóricas e literais, e, desse modo, dividiu-se o experimento em dois grupos. Assim, o participante que visse a expressão metafórica 'Alguns carros são abacaxis mesmo' não viria a expressão literal correlata 'Alguns carros são valiosos mesmo'. Essa estrutura permitiria que os grupos 1 e 2 acabassem interagindo por meio dos seus tempos de reação, pois estes tempos seriam relevantes para nossa pesquisa. Sendo assim o Grupo 1 ficou constituído por 24 expressões no total ( $2+\mathrm{C}-\mathrm{F}, 2-\mathrm{C}+\mathrm{F}, 4$ controles e 16 distratoras), por sua vez o Grupo 2 também seria constituído por 24 expressões no total, sendo ( $2+C-F, 2-C+F, 4$ controles e 16 distratoras), conforme exemplificado pela tabela 3 abaixo, que traz exemplo de cada expressão. 


\begin{tabular}{|c|c|c|}
\hline Expressão Metafórica -C+F & \multicolumn{2}{|c|}{ Algumas frases são pérolas mesmo. } \\
\hline $1^{\circ}$ SEGMENTO & $2^{\circ}$ SEGMENTO & $3^{\circ}$ SEGMENTO \\
\hline Algumas frases & são pérolas & mesmo. \\
\hline Expressão metafórica $+\mathrm{C}-\mathrm{F}$ & \multicolumn{2}{|c|}{ Alguns carros são abacaxis de verdade. } \\
\hline $1^{\circ} \mathrm{SEGMENTO}$ & $2^{\circ}$ SEGMENTO & $3^{\circ}$ SEGMENTO \\
\hline Alguns carros & são abacaxis & de verdade. \\
\hline Expressão literal de $-\mathrm{C}+\mathrm{F}$ & \multicolumn{2}{|c|}{ Algumas frases são ótimas mesmo. } \\
\hline $1^{\circ}$ SEGMENTO & $2^{\circ}$ SEGMENTO & $3^{\circ}$ SEGMENTO \\
\hline Algumas frases & são ótimas & mesmo. \\
\hline Expressão literal de $+\mathrm{C}-\mathrm{F}$ & \multicolumn{2}{|c|}{ Alguns carros são valiosos de verdade. } \\
\hline $1^{\circ}$ SEGMENTO & $2^{\circ}$ SEGMENTO & $3^{\circ}$ SEGMENTO \\
\hline Alguns carros & são valiosos & de verdade. \\
\hline Expressão Distratora & \multicolumn{2}{|c|}{ Algumas crianças são hiperativas na escola.. } \\
\hline $1^{\circ}$ SEGMENTO & $2^{\circ}$ SEGMENTO & $3^{\circ}$ SEGMENTO \\
\hline Algumas crianças & são hiperativas & na escola. \\
\hline
\end{tabular}

Tabela 3. Expressões e segmentos.

\subsection{PROCEDIMENTOS}

As sessões de aplicação dos experimentos foram todas realizadas em um único equipamento notebook, disponibilizado pelo GEPEX/UFF para esse fim, e ocorreram em diversos locais dos quatro campis visitados da UFF em ambiente adequado para aplicação dos testes.

Após os procedimentos de preenchimento de formulários e consentimento, o participante sentava-se à frente do notebook e a ele eram dadas as explicações de como seria a aplicação do teste. Foi realizada uma tarefa de aquecimento de modo que o participante se inteirasse de como seria o seu comportamento durante a aplicação da pesquisa.

Em seguida ao aquecimento, o participante iniciava a tarefa experimental, que consistia em realizar a leitura de frases, divididas em três segmentos, em seguida, responder 'sim' ou 'não' a uma pergunta apresentada. As frases eram apresentadas em ordem aleatória a cada participantes, devido ao procedimento de randomização automática programado para o experimento, de modo que não se tornava possível encontrar algum padrão de distribuiçãa dos estímulos experimentais, de controle e distratoras.Todos os participantes, sem exceção, se mostraram comprometidos ao participarem da pesquisa e a todos eles foi emitido um certificado de participação para ser utilizado como atividade extracurricular.

\subsection{RESULTADOS E DISCUSSÃO}

Inicialmente, é importante lembrar que o objeto de análise deste experimento é o tempo de leitura do segmento crítico que veicula as condições e o controle do referido experimento. Sendo assim, por se tratar de um desenho $2 \times 2$ incompleto, há condições objeto dessa análise, quais sejam, as condições metafóricas que se referem às expressões- $\mathrm{C}+\mathrm{F}$ e $+\mathrm{C}-\mathrm{F}$, 
ao que se acresce a expressão tomada como controle, que se refere às expressões literais correspondentes nos traços $\mathrm{C}$ e F.

As análises estatísticas foram conduzidas por meio do pacote do software ActionStat.Todas as análises foram precedidas pela rodagem do resumo descritivo do programa Action, que consiste numa ferramenta que permite a obtenção de diversas informações sobre o conjunto de dados, como, por exemplo, os valores mínimos e máximos, a soma quadrática, o tamanho da amostra, o primeiro quartil e, além disso, há informações também sobre a média, a mediana, medidas de dispersão, desvio padrão e outros dados que são bem interessantes para a percepção global do experimento.

Da mesma forma, após a rodagem do resumo descritivo, verificou-se o boxplot que consiste num gráfico de caixa utilizado para avaliar a distribuição empírica dos dados, sendo formado pelo primeiro e terceiro quartis, bem como pela mediana. Esses dados reunidos formam bases de limites onde os dados devem estar agrupados e os valores fora desses limites são considerados outliers (valores discrepantes da amostra). Na presente análise, quando se detectou a presença de outliers, fez-se a retida dos mesmos, para finalmente rodar um novo resumo descritivo sem a presença desses dados.

É importante ressaltar ainda que em cada um dos conjuntos de dados foi aplicado o método Kolmogorov-Smirnov para identificar a distribuição dos dados. Com esse método é possível identificar se os dados são normais e, por isso, devem ser analisados em testes paramétricos ou se eles são livres e, em vista disso, devem ser analisados em testes nãoparamétricos. No caso desta pesquisa, todos dados foram identificados como livres e, assim sendo, para as comparações múltiplas, o teste não-paramétrico utilizado foi o Kruskal-Wallis, tendo em vista que este teste possibilita a comparação de três ou mais condições simultaneamente, apresentando, ao final da rodada dos dados, uma tabela de comparações múltiplas, indicando o p-valor dessa comparação. Quando foi verificada a necessidade de fazer comparações entre pares, o teste utilizado foi o Wilcoxon.

\subsubsection{METÁFORA X EXPRESSÕES DE CONTROLE}

Após a realização de todos os procedimentos preliminares para ajuste dos dados (eliminação de outliers, verificação da distribuição dos dados etc.) e, após aplicação do teste definitivo, foi identificada uma diferença estatisticamente significativa entre as expressões metafóricas e seu respectivo controle, com tempos de reação maiores para as metáforas, conforme pode ser vista na tabela 4 que se segue.

\begin{tabular}{|l|l|l|l|l|l|}
\hline & Média & Mediana & $p$-valor & Estatística X ${ }^{2}$ & Desvio Padrão \\
\hline Controle & 1185 & 1072 & \multirow{3}{*}{0,0136} & & 467,57 \\
\cline { 1 - 2 } \cline { 5 - 6 } \\
\cline { 5 - 6 }
\end{tabular}

Tabela 4. Variáveis - valores em milissegundos. 
Como pode ser visto, a metáfora obteve $1211 \mathrm{~ms}$ de mediana enquanto que o controle literal obteve 1072 ms, o que acabou definindo dois conjuntos de dados distintos, o primeiro formado pela metáfora e o segundo formado pelo controle literal.

Os dados da tabela 4 permitem indicar que as variáveis fizeram o efeito esperado, muito embora essa primeira comparação não permita estabelecer os parâmetros desse efeito, o que se verá adiante. Antes de adentrarmos nessa questão, no entanto, vamos observar o gráfico 1 abaixo, para que possamos observar mais claramente o comportamento das médias, medianas e desvio padrão. Como é possível notar por esse gráfico 1, média, mediana e desvio padrão seguem unidos e, conforme uma das colunas do controle literal aumenta, no outro lado esse aumento também acontece. Desse modo, podese afirmar que os dados são harmônicos e, por isso, justifica nossa opção de se trabalhar com a mediana nessa análise, uma vez que, por se tratarem de dados livres, como já citado, os testes não-paramétricos utilizados, levam em consideração a mediana para o desenvolvimento de sua fórmula para detectar o $p$-valor.

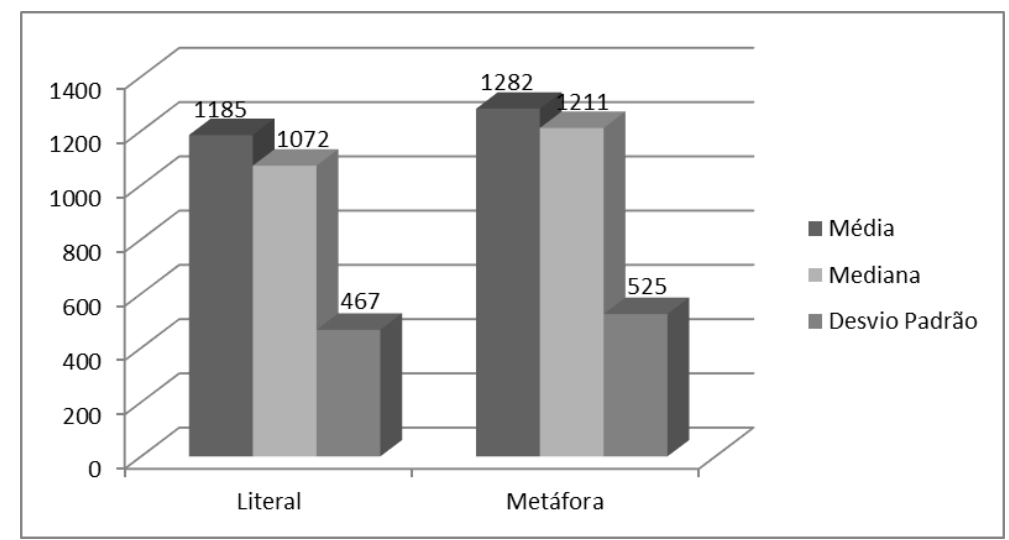

Gráfico 1. Médias, Medianas e Desvio Padrão das Variáveis em milissegundos.

\subsubsection{METÁFORA -C+F X METÁFORA +C-F X CONTROLE}

Ao se contrastar as três condições experimentais, ou seja, Metáforas -C+F, Metáforas +C$\mathrm{F}$ e os controles literais, identificaram-se diferenças e semelhanças, conforme pode ser vista na tabela 5 a seguir.

\begin{tabular}{|l|l|l|l|}
\hline & Média & Mediana & Desvio Padrão \\
\hline Controle Literal & 1185 & 1072 & 467,57 \\
\hline Metáfora+C-F & 1387 & 1296 & 536,89 \\
\hline Metáfora-C+F & 1177 & 1048 & 493,84 \\
\hline
\end{tabular}

Tabela 5. Condições - valores em milissegundos.

Observando a tabela 5, nota-se que a condição metafórica $-\mathrm{C}+\mathrm{F}$ (mediana=1048ms) se assemelha bastante ao controle literal (mediana=1072) e, ambas, por sua vez, se 
diferenciam da condição metafórica $+C-F$ (mediana=1296). Essa característica é um primeiro indício de que as condições metafóricas estão, por alguma razão, desalinhadas no sentido de que a rapidez no processamento não se refere à condição $+C$ e sim à condição $+F$. Outro fator importante a ser destacado da tabela acima, é o fato de que não houve uma diferença significativa do desvio padrão entre as condições e controle. Como forma de visualizar melhor as semelhanças e diferenças apontadas na Tabela 5, apresentamos o gráfico 2 a seguir que retira qualquer dúvida do comportamento das condições e o controle literal.

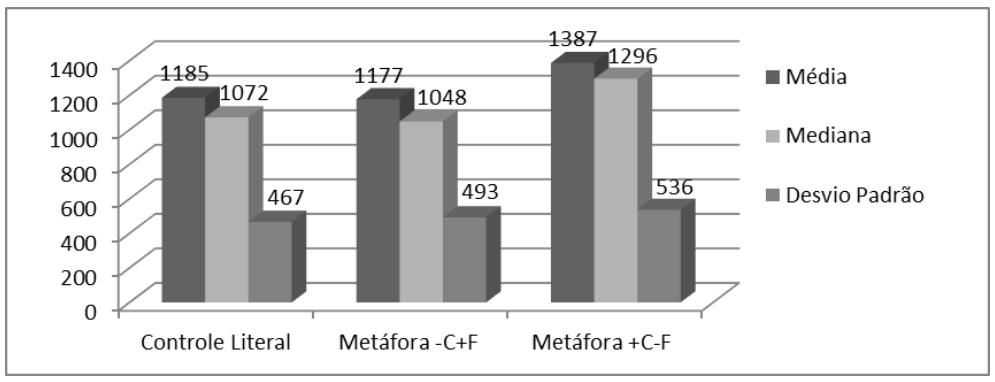

Gráfico 2. Médias, Medianas e Desvio Padrão das Condições.

Como é possível notar agora, fica evidente a paridade na medição de tempo entre o controle literal e a condição metáfora $-\mathrm{C}+\mathrm{F}$, da mesma forma como notamos que a condição metáfora $+\mathrm{C}-\mathrm{F}$ se sobressai nesse gráfico, alcançando os mais altos tempos de processamento. Destaca-se também, que pelo desenho apresentado no gráfico, é possível fazer a justaposição do controle literal com a condição metáfora -C+F quase sem ocorrer diferença em face da equivalência dos dados.

Como pode ser visto na Tabela 6, a comparação entre o controle literal e a condição metáfora $-\mathrm{C}+\mathrm{F}$ não mostrou uma diferença significativa entre essas condições. Por outro lado, a comparação entre as condições metáfora $-\mathrm{C}+\mathrm{F}$ e metáfora $+\mathrm{C}-\mathrm{F}$ apresentou uma diferença significativa. Da mesma forma, ocorreu uma diferença significativa entre o controle literal e a metáfora $+\mathrm{C}-\mathrm{F}$ com o $p$-valor $<0,05$. Estes dados se mostram compatíveis com as previsões experimentais uma vez que se esperava um tempo de reação menor para as metáforas com baixa convencionalidade e altamente familiares em comparação com as metáforas de alta convencionalidade e baixa familiaridade, justamente por interferência da familiaridade da expressão. Assim, esperava-se também que essas metáforas com alta familiaridade, apesar de possuírem baixa convencionalidade, fossem processadas tão rapidamente quanto às expressões literais, o que ocorreu, apontando para um processamento direto dessas expressões, enquanto que no outro polo, ou seja, as metáforas com baixa familiaridade, apesar de possuírem alta convencionalidade, apresentaram uma lentidão significativa em relação às expressões literais, apontando para um processamento indireto dessas expressões. 


\begin{tabular}{|c|c|c|c|c|}
\hline & p-valor & EstatísticaX ${ }^{2}$ & Conjunto1 & Conjunto2 \\
\hline Literal $\times$ Metáfora $-\mathrm{C}+\mathrm{F}$ & 0,754542 & \multirow{3}{*}{22,2681} & \multirow{3}{*}{ Metáfora+C-F } & \multirow[t]{2}{*}{ Metáfora-C+F } \\
\hline Literal $\times$ Metáfora $+\mathrm{C}-\mathrm{F}$ & 0,000036 & & & \\
\hline Metáfora $-\mathrm{C}+\mathrm{F} \times$ Metáfora $+\mathrm{C}-\mathrm{F}$ & 0,0001 & & & Literal \\
\hline
\end{tabular}

Tabela 6. Comparação das condições.

\subsubsection{TRANSFORMANDO AS CONDIÇÕES EXPERIMENTAIS E OS CONTROLES EM QUATRO CONDIÇÕES}

Nesta seção, será feita uma análise das comparações entre as diversas condições a partir de uma dupla de variáveis e ampliando as condições, valendo lembrar que a presente pesquisa optou por criar três comparações específicas, sendo elas: 1) Expressões Metafóricas -C+F; 2) Expressões Metafóricas +C-F; 3) Controles Literais. Agora, aqui, serão ampliadas as condições da pesquisa com objetivo de análise para: 1) Expressões Metafóricas - $\mathrm{C}+\mathrm{F}$; 2) Expressões Metafóricas +C-F; 3) Expressões Literais Correlatas às Expressões Metafóricas $-\mathrm{C}+\mathrm{F}$; 4) Expressões Literais Correlatas às Expressões Metafóricas +C-F.

O gráfico 3 a seguir apresenta as informações básicas da análise: média, mediana e desvio padrão.. O que temos mais uma vez, neste momento, é a divisão do controle literal em duas condições, como será visto a seguir, emparelhadas ao lado das condições metafóricas.

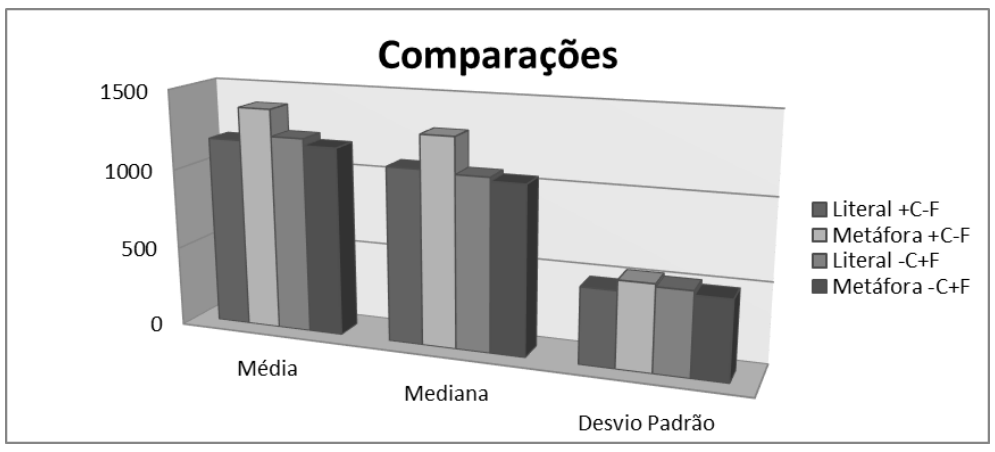

Gráfico 3. Distribuição das quatro condições em milissegundos.

Mais uma vez, fica evidente a semelhança no tempo de reação que envolve o controle literal e a condição metáfora $-\mathrm{C}+\mathrm{F}$, pois mesmo dividindo o controle literal em dois níveis, ainda assim, os dois novos controles literais permanecem alinhados por baixo juntamente com condição metafórica -C+F.Na outra ponta, porém, a condição metafórica $+\mathrm{C}-\mathrm{F}$ permanece isolada acima das outras com tempo de reação maior. No gráfico 3 essa visualização é nítida, demonstrando claramente a diferença entre as metáforas $+\mathrm{C}-\mathrm{F}$ e as demais. 
Outra informação de extrema relevância para a análise é aquela relacionada ao desvio padrão. Note-se que o desvio padrão do controle literal $(+C-F)$ é de $473 m s$, enquanto que da condição metáfora (+C -F) é de 536ms. Por outro lado o desvio padrão do controle literal $(-\mathrm{C}+\mathrm{F})$ é de $519 \mathrm{~ms}$ e o da condição metáfora $(-\mathrm{C}+\mathrm{F})$ é $493 \mathrm{~ms}$. Em todas as condições e controles ocorreram diferenças no desvio padrão, porém, tais diferenças não foram significativas do ponto de vista estatístico. Esse fato sugere que os dados coletados foram bastante homogêneos, sofrendo alteração apenas aqueles dados específicos referentes à familiaridade da expressão.

Os dados apresentados até aqui, vale recordar, indicam que a distribuição das amostras é livre e, por isso, foi necessário aplicar um teste não paramétrico, no caso, o teste de Kruskal-Wallis, em face da necessidade de comparações múltiplas com mais de duas condições. De plano, destacamos que, apesar de serem quatro grupos apresentados (duas condições metafóricas e dois controles literais), a tabela de agrupamento do teste apresentou apenas dois conjuntos distintos, ou seja, 'Conjunto1' e 'Conjunto2', conforme pode ser visto na tabela 7 a seguir, isto é, um conjunto formado pela condição metafórica $+\mathrm{C}-\mathrm{F}$ e outro conjunto formado pela condição metafórica $-\mathrm{C}+\mathrm{F}$ e os dois controles literais.

\begin{tabular}{|c|c|c|c|c|}
\hline & $p$-valor & Estatística $\mathrm{X}^{2}$ & Conjunto 1 & Conjunto 2 \\
\hline Literal -C+F & \multirow[t]{2}{*}{0,851951} & 0,4502 & \multirow{12}{*}{ Metáfora $+\mathrm{C}-\mathrm{F}$} & \multirow{5}{*}{ Literal -C+F } \\
\hline \multicolumn{2}{|l|}{ Literal +C-F } & & & \\
\hline Literal $-\mathrm{C}+\mathrm{F}$ & \multirow[t]{2}{*}{0,851951} & 0,2635 & & \\
\hline \multicolumn{2}{|l|}{ Metáfora $-\mathrm{C}+\mathrm{F}$} & & & \\
\hline Literal $-\mathrm{C}+\mathrm{F}$ & \multirow[t]{2}{*}{0,003258} & 3,3613 & & \\
\hline Metáfora +C-F & & & & \multirow{5}{*}{ Literal +C-F } \\
\hline Literal +C-F & \multirow[t]{2}{*}{0,851951} & 0,1866 & & \\
\hline Metáfora -C+F & & & & \\
\hline Literal +C-F & \multirow[t]{2}{*}{0,000997} & 3,7845 & & \\
\hline Metáfora +C-F & & & & \\
\hline Metáfora -C+F & \multirow[t]{2}{*}{0,001639} & 3,6087 & & \multirow[t]{2}{*}{ Metáfora $-\mathrm{C}+\mathrm{F}$} \\
\hline Metáfora +C-F & & & & \\
\hline
\end{tabular}

Tabela 7. Transformação em quatro condições.

Nas comparações realizadas entre os dois controles literais, não houve diferença significativa, conforme se esperava. O mesmo ocorreu quando as comparações de ambos os controles literais se dev em relação à condição metafórica $-\mathrm{C}+\mathrm{F}$, também de acordo com o aventado nas previsões experimentais.

Por outro lado, quando analisados os resultados da condição metafórica $+\mathrm{C}-\mathrm{F}$, primeiro com o resultado da condição metafórica $-\mathrm{C}+\mathrm{F}$, foi verificada uma diferença significativa. Tal diferença significativa também foi constatada quando comparados os tempos de reação dessa condição metafórica $+\mathrm{C}-\mathrm{F}$ com os dois controles literais separadamente. Assim sendo, os resultados vão na direção prevista e, nesse sentido, fornecem evidências compatíveis com hipótese da pesquisa, sugerindo que o grau de familiaridade interfere no processamento. 


\section{CONSIDERAÇÕES FINAIS}

O presente trabalho nasceu da constatação de que estudos voltados para discutir o processamento psicolinguístico de metáforas não levavam em consideração a familiaridade da expressão metafórica em suas análises ou, em alguns casos, minimizavam os efeitos desse importante aspecto linguístico. Sendo a metáfora construída na interação entre as pessoas, conforme ensinam Lakoff \& Johnson (2002 [1980]) seria óbvia a importância da familiaridade nesse processo, uma vez que esta característica, mais que a convencionalidade do veículo, está ligada ao ambiente de uso da língua.

O experimento elaborado na pesquisa aqui relatada, com as devidas adaptações para - PB, utilizou um modelo experimental consagrado na literatura para aferir o tempo de reação dos falantes da língua durante a leitura de um segmento crítico que continha o veículo metafórico. Os resultados reportados apontam para o efeito da familiaridade na compreensão de frases metafóricas, resgatando, com isso, a importância desse elemento, tantas vezes ignorado nos estudos da área.

Dessa forma, caso a convencionalidade do veículo metafórico fosse o fator principal na compreensão das frases metafóricas, então, fatalmente, as expressões com veículos altamente convencionais, mas pouca familiaridade para os falantes $(+C-F)$ seriam processadas mais rapidamente que as expressões aquelas com menor convencionalidade e alta familiaridade $(-\mathrm{C}+\mathrm{F})$ e apresentariam tempos de reação equivalentes às expressões literais, o que não ocorreu na tarefa experimental conduzida. Conforme os resultados obtidos, aconteceu exatamente o contrário: foram as frases metafóricas $-\mathrm{C}+\mathrm{F}$ que registraram os menores tempos de leitura, indicando que um maior grau de familiaridade parece facilitar o processamento das expressões metafóricas.

É importante destacar, ainda, que o estudo experimental conduzido não levou em consideração o contexto, sendo as frases apresentadas de forma direta, ou seja, afastada do ambiente de uso. Dessa forma, os experimentos conduzidos podem ser questionados por pesquisadores que indicam a necessidade de um contexto para testar as teorias de processamento de frases. Nesse sentido, em pesquisa futura, pretende-se adotar o modelo experimental de Janus e Bever (1985) que utilizaram contexto para atestar o processamento indireto de frases metafóricas. Ainda assim, os resultados aqui apresentados trazem evidências compatíveis com a ideia de que a familiaridade é quem exerce o papel relevante no processamento de metáforas independentemente do grau de convencionalidade do veículo. Assim sendo, se houver alta familiaridade, a expressão metafórica será processada de forma direta, sem priorizar o sentido literal e, em havendo baixa familiaridade, a frase será processada mais lentamente que as expressões literais, mesmo que o veículo metafórico tenha alta convencionalidade. 


\section{REFERÊNCIAS}

BARSALOU, LAWRENCE W. Ad hoc categories. In: Memory\&Cognition, 11 (3), p. 211-227, 1983.

BLACK, M. Modelsandmetaphor. Nova lorque: Cornell University Press, 1962.

BLASKO, D. \& CONNINE, C.M. Effectsoffamiliarityandaptnessonmetaphorprocessing. The Journalof Experimental Psychology. Learning, Memory, andCognition, 19, p. 295-308, 1993.

BOWDLE, B.; GENTNER, D. Metaphorcomprehension: Fromcomparisontocategorization. In: Proceedingsof the twenty-firstannualconferenceof the cognitivesciencesociety. 1999. p. 90-95.

BOWDLE, B.F. \& GENTNER, D. The careerofmetaphor. PsychologicalReview, vol. 112, No. 1, American PsychologicalAssociation, p. 193-216, 2005.

CHIAPPE, D., KENNEDY, J. M. \& SMYKOWSKI, T. Reversibility, aptness, and the conventionalityofmetaphorsandsimiles. MetaphorandSymbol, 18(2), p. 85-105, 2003.

CLARK, H. \& LUCY, P. Understandingwhatismeantfromwhatis said: A study in conversationallyconveyedrequest. Journalof Verbal Learning and Verbal Behavior. 1975. p. 335-359.

Dulcinati, G.; Mazzarella, D.; Pouscoulous, N. \& Rodd, J. Processingmetaphor: The role ofconventionality, familiarityanddominance.UCL, WorkingPapers in Linguistics, 26, p. 72-88. 2014.

FRASER, B. The interpretationof novel metaphors. In A. Ortony (Ed.), Metaphorandthought. Cambridge: Cambridge University Press. 1979.

GENTNER, D. et al. Metaphorislikeanalogy. In: GENTNER, D. et al., (eds.) The AnalogicalMind, p. 199-253, MIT Press, 2001.

GENTNER, D. Structure-mapping: A theoretical framework for analogy. Cognitive Science. 7 (2), pp155-170, 1983.

GENTNER, D. \& BOWDLE, B.F. Convention, Form, andFigurativeLanguageProcessing. Metaphor\&Symbol, 16 (3\&4). Lawrence Erlbaum Associates, Inc., p. 223-247, 2001.

GIBBS, R.W. Contextual effects in understandingindirectrequests. Discourse Processes, 2, p. 1-10, 1979.

Yourwishismycommand: Conventionandcontext in interpretingindirectrequest. Journalof Verbal Learning and Verbal Behavior. 1981. p. 435-444.

GILDEA, P. \& GLUCKSBERG, S. Onunderstandingmetaphor. The role ofcontext. Journalof Verbal Learning and Verbal Behavior. 1983. p. 577-590.

GLUCKSBERG, S. Howmetaphorscreatecategories - quickly. In: GIBBS, R.W. The Cambridge HandbookofMetaphorandThought. Cambridge University Press, p. 67-83, 2008.

. The Psycholinguisticsofmetaphor. Trends in CognitiveSciences, 7(2), p. 92-96, 2003.

Understandingmetaphors. CurrentDirections in Psychological Science, vol. 7, number 2. Cambridge University Press, p. 39-43, 1998.

GLUCKSBERG, S. et al. Onunderstanding non-literal speech: canpeople ignore metaphors? Journalof Verbal Learning and Verbal Behavior, 21, p. 85-98, 1982.

GLUCKSBERG, S.; KEYSAR, B. UnderstandingMetaphoricalComparisons: BeyondSimilarity. PsychologicalReview, v. 97, n. 1, American PsychologicalAssociation, p. 3-18,1990.

GRICE, H.P. LogicandConversation. In: COLE, P. \& MORGAN, J.L. (eds.). SyntaxandSemantics, Vol. 3, Speech Acts. New York: Academic Press, p. 41-58, 1975.

HARRIS, R.J. Comprehensionofmetaphors: A testof the two-stageprocessingmodel. Bulletinof the PsychonomicSociety, Vol. 8 (4), p. 312-314, 1976. 
HOUAISS, A; VILLAR, M. Dicionário Houaiss da língua portuguesa. Rio de Janeiro: Objetiva, 2001.

JANUS, R.; BEVER, T. Processingofmetaphoriclanguage: aninvestigationof the three-

stagemodelofmetaphorcomprehension. JournalofPsycholinguisticResearch, v. 14, n. 5, p. 473-487, 1985.

JENSEN, A. R., \& ROHWER, W. D. The Stroop Color-Word Test: A review. Acta Psychologica. 1966. p. 36-93.

Jones, L.; Estes, Z. Roosters, robins, andalarmclocks: Aptnessandconventionality in metaphorcomprehension. JournalofMemoryandLanguage, v. 55, n. 1, p. 18-32, 2006.

JOHNSON, A. Comprehensionofmetaphorsandsimiles: a reaction time study. MetaphorandSymbolicActivity, II (2), Lawrence Erlbaum Associates, Inc., p. 145-159, 1996.

JUST, M., \& CARPENTER, P. A. A theoryofreading: Fromeyefixationstocomprehension. PsychologicalReview. 1980. p. 329-354.

LAKOFF, G.; JOHNSON, M. Metáforas da Vida Cotidiana. (Coordenação da Tradução Mara Sophia Zanotto) Campinas, SP: Mercados de Letras; São Paulo: EDUC, (2002 [1980])

MILLER, G. Imagesandmodels: similesandmetaphors. In: ORTONY, A. (ed.), Metaphorandthought. Cambridge. Cambridge University Press, p. 202-250, 1979

ORTONY, A. Metaphorandthought. $2^{\text {nd }}$ edition. New York. Cambridge University Press, 1993 [1979].

ORTONY, A.; SCHALLERT, D.; REYNOLDS, R.; ANTOS, S. Interpretingmetaphorsandidioms: Some effectsofcontextoncomprehension. Journalof verbal learningand verbal behavior, v. 17, n. 4, p. 465-477, 1978.

RICCI, A. O processamento psicolinguístico da metáfora: Um estudo experimental no PB. Dissertação defendida no Mestrado de Estudo da Linguagem. Rio de Janeiro: UFF, 2016.

SEARLE, J. Metaphor. In: ORTONY, A. Metaphorandthought. $2^{\text {nd }}$ edition. New York. Cambridge University Press, p. 83-111, 1993 [1979].

SILVA, G. A interferência da familiaridade no processamento de metáfora no PB. Dissertação defendida no Mestrado de Estudo da Linguagem. Rio de Janeiro: UFF, 2018. 